Tropical Journal of Pharmaceutical Research June 2016; 15 (6): 1259-1265

ISSN: $1596-5996$ (print); 1596-9827 (electronic) (C) Pharmacotherapy Group, Faculty of Pharmacy, University of Benin, Benin City, 300001 Nigeria.

All rights reserved.

\title{
Bioprospecting for culturable actinobacteria with antimicrobial properties isolated from rivers in Colombian Orinoquia
}

\author{
Natalia Pastrana-Camacho', Zulma Suárez', Alejandro Acosta-González', \\ Carolina Arango ${ }^{1}$, Brad Haltli ${ }^{2}$, Hebelin Correa ${ }^{2}$, Russel Kerr ${ }^{2}$, Carmenza \\ Duque $^{1}$ and Luis Eduardo Díaz ${ }^{1 *}$ \\ ${ }^{1}$ Universidad de La Sabana, Facultad de Ingenieria, Campus del Puente del Común, Km 7 Autopista Norte de Bogotá. Chia, \\ Colombia, ${ }^{2}$ University of Prince Edward Island, 550 University Avenue, Charlottetown, PE C1A 4P3, Canada
}

*For correspondence: Email: luisdb@unisabana.edu.co; Tel/Fax: +57 18615555 ext 2520

Received: 1 February 2016

Revised accepted: 26 May 2016

\begin{abstract}
Purpose: To Isolate and characterize Actinobacteria with antimicrobial activity from Guaviare River (Colombia).

Methods: Water and sediment samples were collected from Guaviare River. Direct plating, heat and $\mathrm{CaCO}_{3}$ methods were used to isolate Actinobacteria. Six bacterial strains were tested using T-Streak method: Escherichia coli ATCC 23724, Staphylococus aureus ATCC 25923, Acinetobacter baumannii ATCC 19606, Bacillus subtilis ATCC 21556, Klebsiella pneumoniae ATCC 700603, Chromobacterium violaceum ATCC 31532. Strains of Fusarium sp. H24, Trichoderma harzianum H5 and Colletotrichum gloeosporioides were tested using Kirby-Bauer method. Isolates with high antimicrobial activity were selected for further taxonomic identification.

Results: A total of 374 actinobacteria isolates were obtained. Seven isolates exhibited high antimicrobial activity $(p<0.05)$ and were confirmed as members of Streptomycetaceae family. Of these, three isolates showed differential phenotypic and genotypic profiles, indicating that they may represent new species.

Conclusions: To date, this is the first study of this type in Colombian Orinoquia and indicates that this promising source of Actinobacteria from aquatic sediments with the ability to produce antimicrobial secondary metabolites.
\end{abstract}

Keywords: Actinobacteria, Antimicrobial activity, Secondary metabolites, Streptomycetaceae, Phenotypic and genotypic profiles, Colombian Orinoquia

Tropical Journal of Pharmaceutical Research is indexed by Science Citation Index (SciSearch), Scopus, International Pharmaceutical Abstract, Chemical Abstracts, Embase, Index Copernicus, EBSCO, African Index Medicus, JournalSeek, Journal Citation Reports/Science Edition, Directory of Open Access Journals (DOAJ), African Journal Online, Bioline International, Open-J-Gate and Pharmacy Abstracts

\section{INTRODUCTION}

Actinobacteria are a predominant source of antibiotics [1,2] with Streptomyces as the major source of bioactive compounds [3]. Actinobacteria are found in soils although their isolation has focused on other unexplored habitats [2]. Aquatic habitats like rivers have been poorly explored as a source of Actinobacteria with biological activity, despite the fact that river environments can be considered a reservoir of potentially active compounds [4]. The aim of this study was to isolate and to identify Actinobacteria from water and sediments samples of Guaviare river (Colombia) and 
evaluated their ability to produce natural products with antimicrobial activity.

\section{EXPERIMENTAL}

\section{Sample collection}

Water and sediment samples were collected in May 2014 from five different locations in Guaviare River (Colombia): location 1 $\left(2^{\circ} 36^{\prime} 19.2^{\prime \prime} \mathrm{N} \quad 72^{\circ} 42^{\prime} 26.2^{\prime \prime} \mathrm{W}\right)$, location 2 $\left(2^{\circ} 35^{\prime} 24.3^{\prime \prime} \mathrm{N} \quad 72^{\circ} 41^{\prime} 17.2^{\prime \prime} \mathrm{W}\right)$, location 3 $\left(2^{\circ} 34^{\prime} 51.6 " \mathrm{~N} \quad 72^{\circ} 41^{\prime} 34.7^{\prime \prime} \mathrm{W}\right), \quad$ location 4 $\left(2^{\circ} 33^{\prime} 59.4^{\prime \prime} \mathrm{N} \quad 72^{\circ} 41^{\prime} 43.8^{\prime \prime} \mathrm{W}\right), \quad$ location (2॰34'51.4"N 72³9'53.6"W).

\section{Isolation of Actinobacteria}

A direct plating method, a dilute heat method, and $\mathrm{a} \mathrm{CaCO}_{3}$ enrichment method were used for isolation. For direct plating, $1 \mathrm{~g}$ or $1 \mathrm{~mL}$ of sediment/water were spread directly. For the dilute heat method $1 \mathrm{~g}$ or $1 \mathrm{~mL}$ of sediment/water was diluted in $10 \mathrm{~mL}$ sterile filtered river water and heated at $55 \square \mathrm{C}$ for $6 \mathrm{~min}$. For $\mathrm{CaCO}_{3}$ method $1 \mathrm{~g}$ of $\mathrm{CaCO}_{3}$ was mixed with $5 \mathrm{~g}$ sample and incubated at $45 \square \mathrm{C}$ for $1 \mathrm{~h}$ [5]. Each sample from the three pretreatments was then serially diluted to $10^{-3}$ and aliquots $(100 \mu \mathrm{L})$ were spread on oatmeal agar (ISP3), starch casein agar (SCA) and starch casein nitrate agar (SC), supplemented with cycloheximide $(50 \mu \mathrm{l} / \mathrm{mL})$ and nalidixic acid $(10 \mu \mathrm{l} / \mathrm{mL})$. Plates were incubated at $30 \square \mathrm{C}$ for 8 days. Colonies were selected based on morphological features and were archived in $40 \%(\mathrm{v} / \mathrm{v})$ glycerol at $-70 \square \mathrm{C}$.

\section{Screening for antimicrobial activity}

Production of antimicrobial substances and quorum sensing inhibition assay by all isolates was assessed using the T-streak method. Antibiosis was indicated by visually observable growth inhibition of the target organisms, and results were recorded as follows: ++ (complete inhibition), + (partial inhibition), - (no inhibition).

\section{Antifungal activity}

Antifungal activities were determined using the Kirby-Bauer method. Inhibition zones were recorded as follows: diameter $>20 \mathrm{~mm}$ : +++ (good activity), diameter between 10-20: ++ (moderate activity), diameter < $10 \mathrm{~mm}$ : + (weak activity) and - (no activity).

\section{Macroscopic and microscopic features}

For isolates with high antimicrobial activity, different culture media were used. Media: tryptone/yeast extract agar (ISP1), malt/yeast extract agar (ISP2), oatmeal agar (ISP3), inorganic salts starch agar (ISP4), glycerol asparagine agar (ISP5) and starch casein agar SCA (Table 2).

\section{Carbon source profiles}

Isolates were grown in 12 well microplates with 5 $\mathrm{mL}$ basal agar $\left[\left(\mathrm{NH}_{4}\right)_{2} \mathrm{SO}_{4} 2.64 \mathrm{~g} / \mathrm{L}, \mathrm{KH}_{2} \mathrm{PO}_{4} 2.38\right.$ $\mathrm{g} / \mathrm{L}, \mathrm{K}_{2} \mathrm{HPO}_{4} 4.31 \mathrm{~g} / \mathrm{L}, \mathrm{MgSO}_{4} \times 7 \mathrm{H}_{2} \mathrm{O} 1.0 \mathrm{~g} / \mathrm{L}$ and $1.0 \mathrm{ml} / \mathrm{L}$ trace element solution $\left(\mathrm{CuSO}_{4} \mathrm{x}\right.$ $5 \mathrm{H}_{2} \mathrm{O} 0.64 \mathrm{~g} / \mathrm{L}, \mathrm{FeSO}_{4} \times 7 \mathrm{H}_{2} \mathrm{O} 0.11 \mathrm{~g} / \mathrm{L}, \mathrm{ZnSO}_{4} \times$ $\left.7 \mathrm{H}_{2} \mathrm{O} 0.15 \mathrm{~g} / \mathrm{L}, \mathrm{MnCl}_{2} \times 4 \mathrm{H}_{2} \mathrm{O}\right)$ ], supplemented with $1 \%(\mathrm{w} / \mathrm{v})$ of a selected carbon source. Lactose, galactose, maltose, ribose, sucrose, xylose, inositol, fructose and carboxymethylcellulose were tested, with glucose as positive control, and a "no carbon source well", as negative control. Growth was monitored after 5 days and results were recorded as follows: Growth equivalent to the negative control $(-)$, growth better than negative control but not as robust as the positive control $(+)$, growth equivalent to the positive control growth $(++)$, growth better than the positive control $(+++)$ (Table 3).

\section{Taxonomical identification}

Taxonomic identification was obtained by PCR amplification, sequencing and analysis of the nearly complete $16 \mathrm{~S}$ rRNA locus using primers 27F (5'-AGAGTTTGATCMTGGCTCAG-3') and 1492R (5'- TACGGYTACCTTGTTACGACTT-3'). $P C R$ thermal cycling is described elsewhere [6]. PCR products were sequenced by Macrogen (Korea). Sequences were assembled using the CLC Main Workbench 7.0 program and compared with SILVA Living Tree Project (release109) database [7]. Sequences were aligned using SINA [8] and the phylogenetic tree was constructed using maximum parsimony DNA distance algorithm with ARB 5.5 [9].

\section{Statistical analysis}

The data obtained were analyzed with SAS 9.4 software using a factorial model 9x7 (nine microorganism and seven isolates) with Fisher's protected least significant difference (LSD) test for means comparison. A value of $p<0.05$ was considered statistically significant.

\section{RESULTS}

\section{Isolation of Actinobacteria}

A large number (374) of suspected Actinobacteria colonies were isolated. Pre- 
treatment with $\mathrm{CaCO}_{3}$, produced 275 isolates and application of the direct plating method yielded 99 isolates, whereas heat treatment did not produce isolates.

\section{Antimicrobial activity}

A number of 65 isolates (17.4 \%) showed antibacterial activity against at least one of the bacteria tested. A significant number of isolates $(149 ; 39.8 \%)$ also exhibited antifungal activity to at least one of the fungus tested, showing inhibitions halos between $10-35 \mathrm{~mm}$, corresponding to a good or moderate activity, as shown in Figure 1. Statistical analysis showed an interaction between the two factors (Actinobacteria isolates and fungus strain), implying that each Actinobacteria isolate was most effective with a certain fungus strain.

Seven isolates displaying high antibacterial and antifungal activities were selected for further study. This group consisted of strains with at least moderate activity $(++)$ or high activity $(+++)$ against 1 fungal strain and 2 tested bacteria (Table 1).

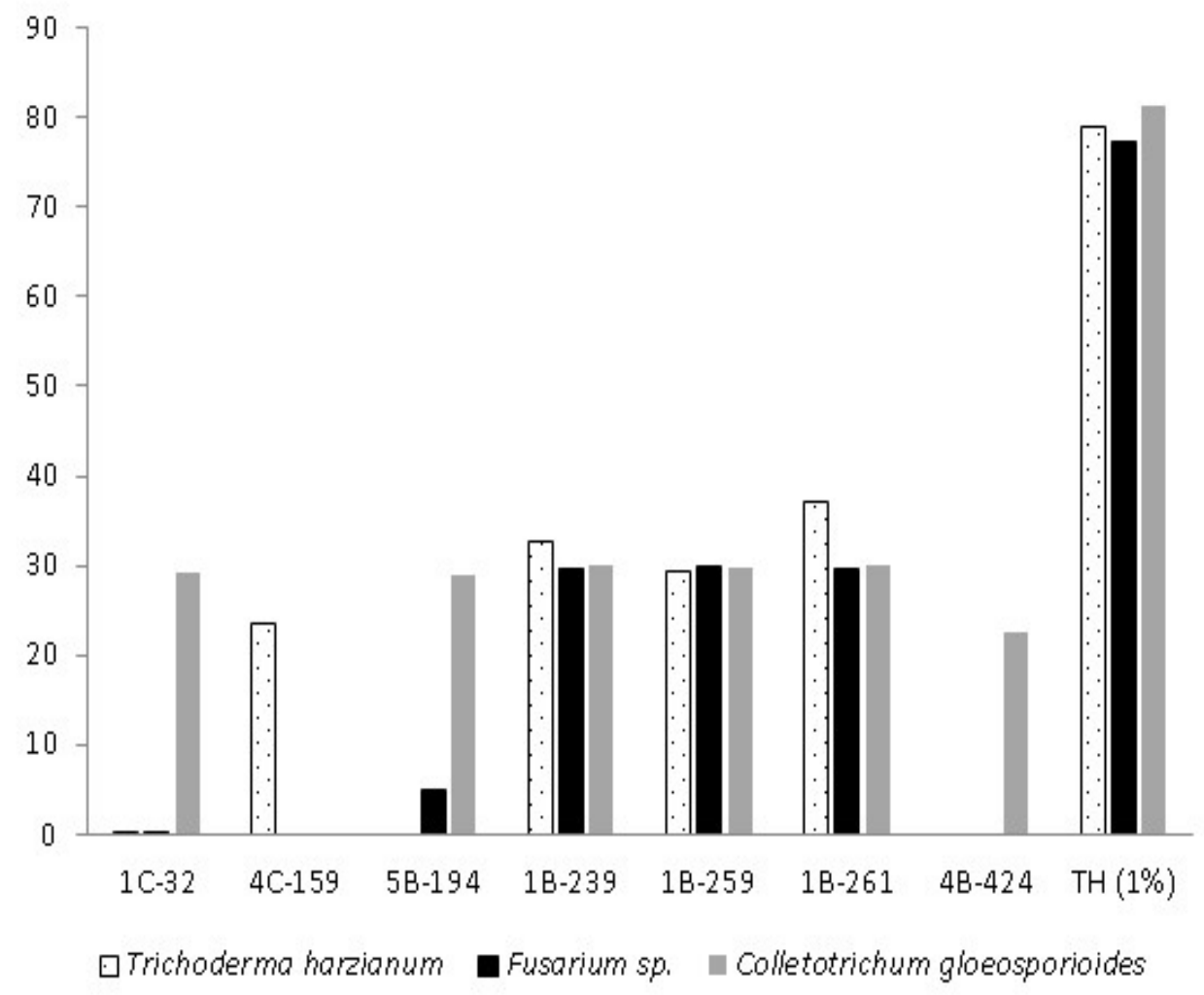

Figure 1: Diameter of inhibition halos of actinobacteria isolates with antifungal activity against Trichoderma harzianum, Fusarium sp and Colletotrichum gloeosporioides. Terbinafine hydrochloride $1 \%(\mathrm{TH})$ was used as control

Table 1: Antimicrobial activity of seven selected strains against fungi and bacterial strains

\begin{tabular}{|c|c|c|c|c|c|c|c|c|c|}
\hline \multirow[b]{2}{*}{$\begin{array}{l}\text { Isolated } \\
\text { strain }\end{array}$} & \multicolumn{8}{|c|}{ Microorganism } & \multirow[b]{2}{*}{9} \\
\hline & 1 & 2 & 3 & 4 & 5 & 6 & 7 & 8 & \\
\hline 1B-239 & ++ & + & - & - & - & ++ & +++ & +++ & + \\
\hline 1B-259 & + & ++ & + & ++ & - & + & ++ & ++ & - \\
\hline 1B-261 & - & ++ & - & + & - & + & ++ & +++ & ++ \\
\hline $1 \mathrm{C}-32$ & + & - & + & + & - & - & - & ++ & ++ \\
\hline 4B-424 & - & + & - & + & - & - & - & +++ & - \\
\hline $4 C-159$ & + & ++ & ++ & ++ & - & + & - & +++ & - \\
\hline 5B-194 & - & - & + & + & - & ++ & + & +++ & - \\
\hline
\end{tabular}

Microorganisms 1: E. coli. 2: $\underline{S}$. aureus. 3: $\underline{A}$. baumannii. 4: $\underline{B}$. subtilis. 5: K. pneumoniae. 6: $\underline{T}$. harzianum H5. 7:

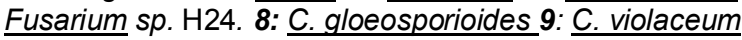


Table 2: Morphological characteristics of isolates and closest relatives*

\begin{tabular}{|c|c|c|c|c|c|c|c|}
\hline \multirow[b]{2}{*}{ Isolate/closest relative } & & \multicolumn{6}{|c|}{ Medium } \\
\hline & & SCA & ISP1 & ISP2 & ISP3 & ISP4 & ISP5 \\
\hline \multirow{3}{*}{ 1B-239 } & AM & W & W & W & $\mathrm{B}$ & & \\
\hline & SM & LGB & $\mathrm{C}$ & $\mathrm{Br}$ & $\mathrm{W}$ & $\mathrm{YBr}$ & LY \\
\hline & RS & $\mathrm{LBr}$ & LY & DY & $\mathrm{B}$ & LY & $\mathrm{B}$ \\
\hline \multirow[t]{2}{*}{ S. Iunalinharesii } & SM & NR & NR & NR & NR & $\mathrm{YBr}$ & Ybr \\
\hline & AM & LG & W & $\mathrm{B}$ & W & OG & W \\
\hline \multirow[t]{2}{*}{ 1B-259 } & SM & W & $\mathrm{C}$ & W & $\mathrm{C}$ & W & $\mathrm{B}$ \\
\hline & $\mathrm{RS}$ & LY & $\bar{Y}$ & $\overline{L Y}$ & $\mathrm{Y}$ & $\mathrm{Y}$ & $\mathrm{B}$ \\
\hline \multirow[t]{2}{*}{ S. kasugaensis } & AM & NR & $\mathrm{NR}$ & CGB & TW & OG & PB \\
\hline & AM & W & LO & LOG & W & LBG & W \\
\hline \multirow[t]{3}{*}{ 1B-261 } & SM & C & W & W & C & W & C \\
\hline & RS & $\mathrm{B}$ & B & $\mathrm{O}$ & W & DY & $\mathrm{B}$ \\
\hline & AM & W & $\mathrm{YBr}$ & W & $\mathrm{G}$ & GP & W \\
\hline \multirow[t]{2}{*}{$1 C-32$} & SM & $\mathrm{GBr}$ & $\mathrm{Br}$ & $\mathrm{GBr}$ & $\mathrm{C}$ & $\mathrm{B}$ & DY \\
\hline & $\mathrm{RS}$ & $\mathrm{BY}$ & $\mathrm{YBr}$ & DY & $\mathrm{GrY}$ & $\mathrm{B}$ & $\mathrm{Y}$ \\
\hline \multirow[t]{2}{*}{ K. putterlickiae } & AM & NR & NR & DG & $\mathrm{G}$ & $\mathrm{DG}$ & DG \\
\hline & $\mathrm{AM}$ & & & $\mathrm{G}$ & $\mathrm{W}$ & $\mathrm{W}$ & $\mathrm{W}$ \\
\hline \multirow[t]{2}{*}{$4 B-424$} & SM & $\bar{Y}$ & DY & $\bar{Y}$ & $\bar{Y}$ & $\mathrm{Br}$ & LY \\
\hline & RS & $\bar{Y}$ & DY & $\bar{Y}$ & LY & $\mathrm{Br}$ & LY \\
\hline S. variegatus & AM & NR & NR & NR & WLP & NR & WLP \\
\hline \multirow[t]{2}{*}{ S. flavofungini } & AM & NR & NR & NR & NR & WOY & NR \\
\hline & AM & BR & $\mathrm{LBr}$ & $\mathrm{DBr}$ & $\mathrm{Br}$ & $\mathrm{GBr}$ & WPP \\
\hline \multirow[t]{2}{*}{$4 C-159$} & SM & $\mathrm{LBr}$ & GrY & $\mathrm{C}$ & $\mathrm{C}$ & C & $\mathrm{C}$ \\
\hline & RS & DY & $\mathrm{O}$ & $\mathrm{O}$ & $\mathrm{Y}$ & $\mathrm{Gr}$ & BY \\
\hline S. griseofuscus & AM & NR & NR & \multicolumn{4}{|c|}{ Red or gray color series } \\
\hline S. murinus & RS & NR & NR & YMR & GY & YMR & GY \\
\hline \multirow[t]{2}{*}{ S. costaricanus } & SM & NR & NR & LY & $\mathrm{Br}$ & $\mathrm{Y}$ & LY \\
\hline & AM & $\mathrm{Br}$ & GG & $\mathrm{LBr}$ & $\mathrm{LBr}$ & $\mathrm{BBr}$ & W \\
\hline \multirow[t]{2}{*}{$5 B-194$} & SM & PG & PY & $\mathrm{PBr}$ & DBB & $\mathrm{B}$ & PR \\
\hline & RS & $\mathrm{GrBr}$ & $\mathrm{GrBr}$ & $\mathrm{Br}$ & DY & $\mathrm{B}$ & $\mathrm{BO}$ \\
\hline S. misionensis & RS & NR & NR & $\mathrm{OBr}$ & $\overline{\mathrm{GY}}$ & $\mathrm{YBr}$ & $\mathrm{OBr}$ \\
\hline S.phaeoluteichromatogene & AM & NR & NR & NR & $\mathrm{Br}$ & NR & NR \\
\hline
\end{tabular}

Table 3: Carbon source utilization of selected isolates

\begin{tabular}{|c|c|c|c|c|c|c|c|c|c|c|}
\hline \multirow[b]{2}{*}{ Isolate } & \multicolumn{10}{|c|}{ Carbon source } \\
\hline & 1 & 2 & 3 & 4 & 5 & 6 & 7 & 8 & 9 & 10 \\
\hline 1B-239 & ++ & - & +++ & +++ & ++ & - & - & + & - & - \\
\hline 1B-259 & ++ & - & +++ & +++ & ++ & - & - & +++ & ++ & - \\
\hline 1B-261 & ++ & + & +++ & +++ & +++ & - & ++ & +++ & + & - \\
\hline 1C-32 & ++ & - & + & +++ & - & + & - & - & ++ & - \\
\hline 4B-424 & ++ & - & + & ++ & ++ & - & - & + & - & - \\
\hline 4C-159 & ++ & + & ++ & +++ & +++ & - & ++ & - & + & - \\
\hline 5B-194 & ++ & +++ & +++ & +++ & +++ & + & +++ & + & +++ & - \\
\hline
\end{tabular}

Carbon source 1: glucose 2: lactose 3: galactose 4: maltose 5: ribose 6: sucrose 7: xylose 8: inositol 9: fructose 10: carboxymethylcellulose Growth equivalent to the negative control (-), growth better than the negative control but not equivalent to the positive control (+), growth equivalent to the positive control growth (++), growth better like the positive control (+++)

\section{Taxonomical identification}

16S rDNA sequences were compared with SILVA Living Tree Project (release 109) database, which confirmed that all isolates belonged to Streptomycetaceae family with similarity values beyond $98 \%$ to the closest neighbors. Maximum parsimony phylogenetic analyses is shown in Figure 2.

\section{DISCUSSION}

Enhanced recovery of Actinobacteria using the $\mathrm{CaCO}_{3}$ pretreatment may be explained by the resulting increase in $\mathrm{pH}$ which promotes the growth of Actinobacteria propagules [10]. Several Actinobacteria isolation protocols, utilize heating and drying stages to select heat-resistant microorganisms capable of forming spores [11]. 


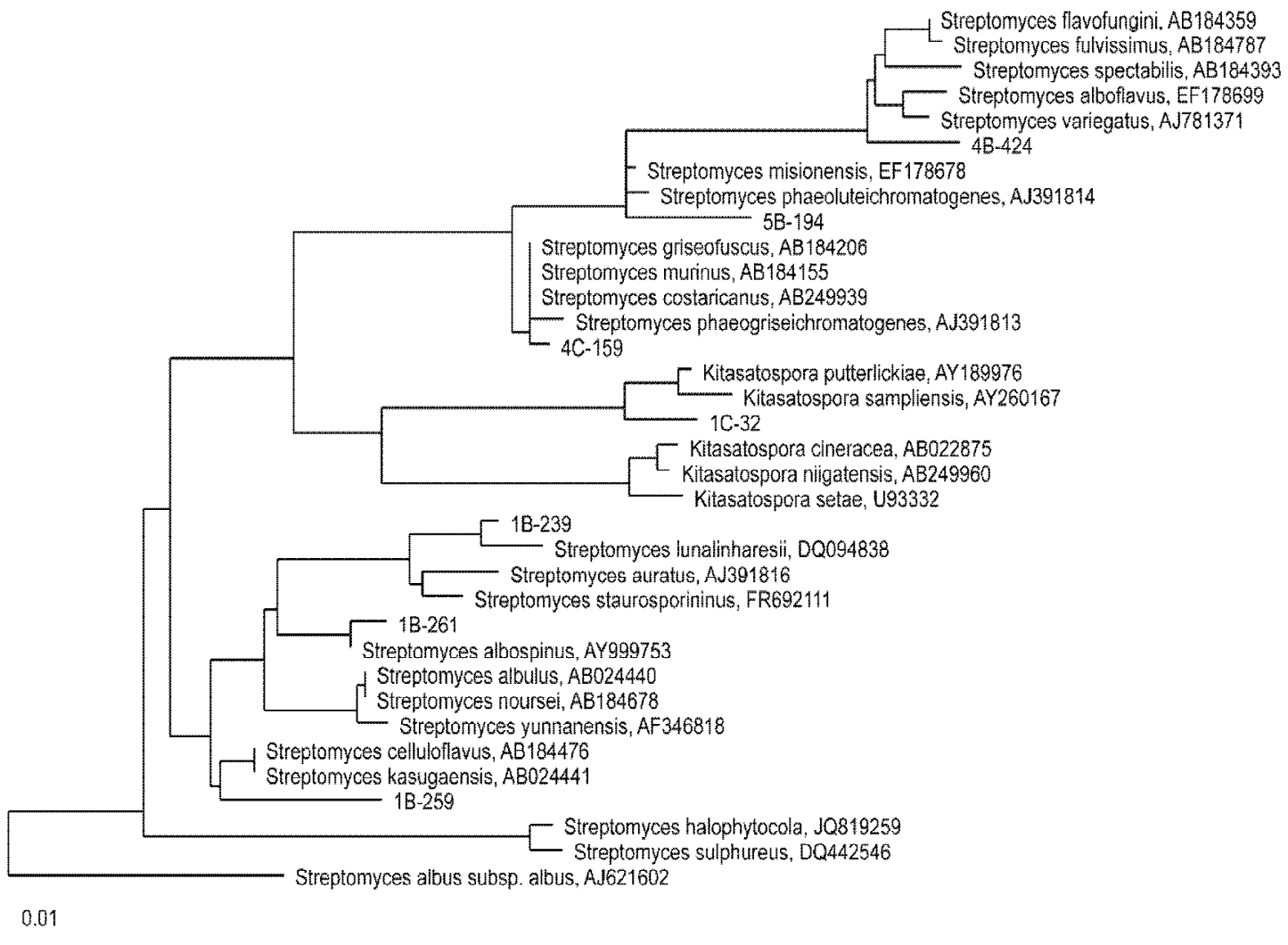

Figure 2: Phylogenetic tree of selected isolates constructed using maximum parsimony method

Williams and coworkers have suggested thermal treatments between $40-50{ }^{\circ} \mathrm{C}$ for $2-16 \mathrm{~h}$ for selective isolation of Actinobacteria, reducing significantly accompanying flora [12]. Probably this method was not successful due the temperature used compared with exposure time.

The results suggest that all 7 strains characterized in this study belong to the Streptomycetaceae family. Isolate 5B-194 had close similarity with two Streptomyces species, but according to similarities with macroscopic characteristics (table 2) and carbon source utilization it's probable that this isolate belongs to Streptomyces misionensis species. Isolate 4C159 showed close similarity with three Streptomyces species, however doing the comparison between macroscopic characteristics and carbon source utilization was not possible to suggest which species belongs because differences were significant. Considering that most recent definition of a prokaryotic species based on 16S rDNA sequence similarity is determined by a minimum similarity of $98.7 \%$ [24] strains 1B-259, 1C-32 and 4B-424 showed similarity levels to their closest neighbours below this value, suggesting that these isolates may represent new species from the Streptomycetaceae family. These strains show some differences in terms of macroscopic characteristics and carbon source utilization respect to closest neighbours. Strains 1B-239 and 1B-261, identified as Streptomyces lunalinharesii and Streptomyces albospinus, respectively. Streptomyces lunalinharesii has reported activity against Aspergillus niger, Candida albicans, Bacillus pumilus and Desulfovibrio alaskensis [13,14], as well as several phytopathogenic fungi [15]. Streptomyces albospinus produces the fungicide phenamide against Phaeosphaeria nodorum [16] and two new compounds with antibacterial activity against methicilin resistant $S$. aureus (MRSA) [17].

Of all isolates obtained (374 actinobacteria isolates), a large number of them were active against Bacillus subtilis, consistent with previous studies, [18] and against $A$. baumannii and $K$. pneumonia which are two carbapemen-resistant microorganisms that have become problematic due to the absence of effective medication [19]. Four strains isolated in this study showed inhibition of $A$. baumannii, with two of them being able to inhibit $K$. pneumoniae. Considering the fact that $K$. pneumonia used in this study is resistant to multiple antibiotics including the carbapenem-iminipem it is likely that isolates 
able to inhibit its growth are producers of new compounds. Our results also suggest a remarkable potential for antifungal agents, in particular against $C$. gloeosporioides. Fungi belonging to the genus Colletotrichum has been classified as disease-causing fungus affecting almost all agricultural crops in the world [20] as well as Fusarium spp [21]. For this reason, several actinobacterial isolates identified in this study may be potential candidates for biocontrol purposes as 43 showed inhibition of the three fungal strains tested.

Chromobacterium violaceum was included in this study to screen the strains for production of inhibitors of AHL-quorum sensing. According to these results, 257 isolates were able to inhibit pigment production in $C$. violaceum without altering the growth of bacteria, which represents an enormous potential, representing an alternative to the use of antibiotics and their induced resistance [22]. In this area, Actinobacteria are of interest due to their capacity to produce and secrete secondary metabolites that eventually can act as inhibitors of $\mathrm{N}$-acyl-L-homoserine lactones (AHL), which mediate most Quorum sensing processes in Gram negative bacteria [23].

\section{CONCLUSION}

The results indicate a high abundance of culturable Actinobacteria in sediments from Guaviare River in Colombia, and also revealed a remarkable potential for 7 strains, selected as potential sources of antimicrobial compounds. Furthermore, three isolates showed differential phenotypic and genotypic profiles in comparison to those reported for the most closely related Streptomyces and Kitasatospora species, indicating they may represent new species. To the best of our knowledge, this is the first study of its type in the Colombian Orinoquía region and may help to identify new bacterial species with antimicrobial properties in this region.

\section{ACKNOWLEDGEMENT}

La Sabana University (Colombia) is acknowledged for support for this study through Grant no. ING-137-2013.

\section{DECLARATIONS}

\section{Conflict of Interest}

No conflict of interest associated with this work.

\section{Contribution of Authors}

The authors declare that this work was done by the authors named in this article and all liabilities pertaining to claims relating to the content of this article will be borne by them.

\section{REFERENCES}

1. Sharma D, Kaur $T$, Chadha BS, Manhas RK. Antimicrobial activity of actinomycetes against multidrug resistant Staphylococcus aureus, E. coli and various other pathogens. Trop J Pharm Res 2011; 10: 801-808.

2. Lam KS. Discovery of novel metabolites from marine actinomycetes. Curr Opin Microbiol 2006; 9: 245-251.

3. Solecka J, Zajko J, Postek M, Rajnisz A. Biologically active secondary metabolites from actinomycetes. Cent Eur J Biol 2012; 7: 373-390.

4. Duncan K, Haltli B, Gill KA, Kerr RG. Bioprospecting from marine sediments of New Brunswick, Canada: exploring the relationship between total bacterial diversity and actinobacteria diversity. Mar Drugs 2014; 12: 899-925.

5. Gurung TD, Sherpa C, Agrawal PA, Lekhak B. Isolation and characterization of antibacterial actinomycetes from soil samples of Kalapatthar, Mount Everest region. Nepal J Sci Technol 2009; 10: 173-182.

6. Yarza P, Richter M, Peplies J, Euzeby J, Amann R, Schleifer KH, Ludwig W, Glöckner FO, Rosselló-Móra R. The All-Species Living Tree project: A 16S rRNA-based phylogenetic tree of all sequenced type strains. Syst Appl Microbiol 2008; 31: 241-250.

7. Pruesse E, Peplies J, Glöckner FO. SINA: Accurate highthroughput multiple sequence alignment of ribosomal RNA genes. Bioinformatics 2012; 28: 1823-1829.

8. Ludwig W, Strunk O, Westram R, Richter L, Meier H, Yadhukumar, Buchner A, Lai T, Steppi S, Jobb G, et al. ARB: a software environment for sequence data. Nucl Acids Res 2004; 32: 1363-1371.

9. Quast C, Pruesse E, Yilmaz P, Gerken J, Schweer T, Yarza P, Peplies J, Glöckner FO. The SILVA ribosomal RNA gene database project: improved data processing and web-based tools. Nucl Acids Res 2013; 41: D590596.

10. Qin S1, Li J, Chen HH, Zhao GZ, Zhu WY, Jiang CL, Xu $\mathrm{LH}, \mathrm{Li}$ WJ. Isolation, diversity, and antimicrobial activity of rare actinobacteria from medicinal plants of tropical rain forests in Xishuangbanna, China. Appl Environ Microbiol 2009; 75: 6176-6186.

11. Williams ST, Shameemullah M, Watson ET, Mayfield Cl. Studies on the ecology of actinomycetes in soil-VI. The influence of moisture tension on growth and survival. Soil Biol Biochem 1972; 4: 215-225.

12. Kämpfer $P$, Glaeser $S$, Parkes $L$, van Keulen $G$, Dyson $P$. The Family Streptomycetaceae. In: Rosenberg, E., DeLong, E., Lory, S., Stackebrandt, E., Thompson, F. (Ed.), The Prokaryotes. Springer Berlin Heidelberg, Berlin 2014; pp: 889-1010. 
13. Pacheco da Rosa J, Korenblum E, Franco-Cirigliano MN, Abreu F, Lins U, Soares RMA, Macrae A, Seldin L, Coelho RRR. Streptomyces lunalinharesii Strain 235 Shows the Potential to Inhibit Bacteria Involved in Biocorrosion Processes. Biomed Res Int 2013; 2013: 110.

14. Macrae A, Coelho RR, Peixoto R, Rosado A. Tropical Soil Microbial Communities. In: Rosenberg, E., DeLong, E., Lory, S., Stackebrandt, E., Thompson, F. (Ed.), The Prokaryotes. Springer Berlin Heidelberg, Berlin 2013; pp: 85-95.

15. Makkar NS, Nickson TE, Tran M, Biest N, MillerWideman M, Lawson J, McGary $\mathrm{Cl}$, Stonard $R$. Phenamide, a fungicidal metabolite from Streptomyces albospinus A19301. Taxonomy, fermentation, isolation, physico-chemical and biological properties. I Antibiot 1995; 48: 369-374.

16. Yu L, Dai Hf, Zhao Yx, Zuo Wj, Dong Wh, Mei Wl, Zeng Hc. Two new sesquiterpene derivatives from soil actinomycete Streptomyces albospinus 15-4-2. Phytochem Lett 2013; 6: 110-112.

17. Brötz E, Kulik A, Vikineswary S, Lim CT, Tan GYA, Zinecker $H$, Imhoff JF, Paululat $T$, Fiedler HP. Phenelfamycins $G$ and $H$, new elfamycin-type antibiotics produced by Streptomyces albospinus Acta 3619. J Antibiot 2011; 64: 257-266.

18. Zhu H, Swierstra J, Wu C, Girard G, Choi YH, van Wamel W, Sandiford SK, van Wezel GP. Eliciting antibiotics active against the ESKAPE pathogens in a collection of actinomycetes isolated from mountain soils. Microbiology 2014; 160: 1714-1725.

19. Rodríguez-López ÉS, Cárdenas-Soriano E, HernándezDelgado S, Gutiérrez-Diez A, Mayek-Pérez N. Análisis de la infección de Colletotrichum gloeosporioides (Penz.) Penz. \& Sacc. de frutos de aguacatero. Rev Bras Frutic 2013; 35: 898-905.

20. Aoki T, O'Donnell K, Geiser D. Systematics of key phytopathogenic Fusarium species: current status and future challenges. J Gen Plant Pathol 2014; 80: 189201.

21. Zhu H, He CC, Chu QH. Inhibition of quorum sensing in Chromobacterium violaceum by pigments extracted from Auricularia auricular. Lett Appl Microbiol 2011; 52: 269-274.

22. Chankhamhaengdecha S, Hongvijit S, Srichaisupakit A, Charnchai $P$, Panbangred W.. Endophytic Actinomycetes: A novel source of potential acyl homoserine lactone degrading enzymes. Biomed Res Int 2013; 2013: 1-8.

23. Park SY, Kang HO, Jang HS, Lee JK, Koo BT, Yum DY. Identification of extracellular $\mathrm{N}$-acylhomoserine lactone acylase from a Streptomyces $s p$. and its application to quorum quenching. Appl Environ Microbiol 2005; 71: 2632-2641.

24. Intra B, Matsumoto $A$, Inahashi $Y$, Omura $S$, Panbangred $W$, Takahashi $Y$. Streptosporangium jomthongense $s p$. nov., an actinomycete isolated from rhizospheric soil and emendation of the genus Streptosporangium. Int $J$ Syst Evol Microbiol 2014; 64: 2400-2406. 